\title{
BUILDING A SMARTER CITY
}

\author{
Roy Woodhead ${ }^{1 *}$ \\ ${ }^{1}$ Sheffield Business School, Sheffield Hallam University, City Campus, Howard Street, \\ Sheffield, S1 1WB, UK
}

(Received: December 2018 / Revised: December 2018 / Accepted: December 2018)

\begin{abstract}
This article is adapted from a paper presented at the prestigious "CSID AUN-SCUD International Conference on Sustainable Infrastructure and Urban Development" held in Jakarta in November of 2018. It draws on the literature to develop a historical interpretation that explains why the world is changing as it is and how it might subsequently evolve.

The paper recognizes that we live in a period that marks the end of an old era and the start of a new digitally enabled era. The role of creativity becomes ever more important as the evolution of the Internet unlocks new opportunities around innovations in IoT, Big Data, and Cloud Compute, to name but a few. While some organizations try to repeat what they have done in the past, only this time with digital technology, others (e.g., Elon Musk) set out to reinvent value chains and, in so doing, move economic power away from established players. It is by seeing the strategic, tactical, and operational possibilities in an integrated way that substantive ideas emerge (e.g., Airbnb becoming the largest hotel chain without owning a single hotel). In particular, our paper explores the intersect between the evolution of our cities and levels of awareness, of consciousness, that mark the maturity of urban evolution (i.e., the "smartness" of the city and its citizens). Finally, it reports on an attempt to push such an evolutionary improvement in the UK city of Sheffield.
\end{abstract}

Keywords: Smart city; Sustainable infrastructure; UK city of Sheffield; Urban evolution

\section{INTRODUCTION}

In this paper we begin by outlining the size of the problem humans face as our cities are expected to grow whilewe struggle to manage them today.We explore a number of perspectives on what a city is and what a smart city could be. As we do this we develop insights that help us to form our own view of what is needed.

By 2050 we expect $68 \%$ of all humans will live in a city (UN, 2018). In the UK we also face an expanding demographic skew toward more elderly citizens. The need for innovation is upon us as many UK cities are still escaping post-industrialism, and local government is struggling to cope under reduced budgets. Why would we expect future cities to cope under even more pressure unless we innovate?

We need to learn from history - to explore ideas of what a smart city could be. We argue a smart city must transcend the"disconnected" consciousness held by different stakeholder communities and in different social hierarchical layers. The aim is to unlock networksynergies as citizens become more empowered to make good choices through better real-time information

\footnotetext{
*Corresponding author's email: r.m.woodhead@shu.ac.uk, Tel. +44 (0)114 2254085 Permalink/DOI: https://doi.org/10.14716/ijtech.v9i7.2734
} 
flows.

Increasing the level of consciousness among citizens will also improve the possibility of new solutions to emerge - new realizations of "need" becoming the necessity that is the mother of invention. Data and information can unlock new relationships between communities and local government as new possibilities emerge. For example, knowing flooding will happen "a priori" means citizens can be moved to safety in good time and with reduced stress as local government moves to proactive rather than reactive management approaches. Technology can enable empowered and informed citizens to play a much more proactive role in tackling what today seems like insurmountable problems. New business needs will reshape numerous value chains. Our cities are about to transform, and we need to be ready.

We report on an action research project that is running Smart City Hackathons around a LoRaWAN technology called "The Things Network." The intent is to build a foundational capability in Sheffield. We hope other academics can learn from our experiences and develop collaborative smart city research agendas with numerous inter-city benefits.

Finally we report on an action research project where we ran five Smart City Hackathons tobuild a foundational capability. This was around a LoRaWAN technology called "The Things Network." Here wegive a high-level overview of the technical agenda.

\section{WHAT IS A SMART CITY?}

In 2014 the United Nations (UN, 2014) predicted that by 2050, some 66\% of all humans will live in a city, most in the Far East. In 2018 they increased their prediction to 68\% (UN, 2018). The estimate's trend is upward.

When we look at UK cities today and problems such as crime, violence, food poverty, fuel poverty, traffic congestion, etc., it is clear to see we cannot really cope with today's level of population density in our cities. This picture seems to repeat in many other cities around the world. Our current ideas of what makes a city function are not "sustainable" in many senses of that word (e.g., business continuity, environmental, civic values, etc.). We need to be more intelligent and start evolving toward the idea of a smart city - a city that not only copes but is experienced positively by most of its citizens, if not all of them.

It seems reasonable to expect a smart city to be somehow more intelligent than a non-smart city to warrant the label "smart." How could we recognize that improvement?

Goldsmith and Crawford (2014) explore the idea of a smart city, a "Responsive City," from the perspective of local government (e.g., city hall). For them, the challenge is to move local government from a bureaucratic modus operandi that focuses on processes and procedures to a more outcome-oriented logic. This would lead to more informed governance of a city. However, in the main they still see a top-down hierarchy as key, and so the challenge they see is how to help leaders make better decisions. The problem history shows with "top down" approaches, especially under "command and control" management, is they often carry many assumptions about the detailed operational level (e.g., Napoleon's failed march to Moscow underestimating the capability of his own supply chain).

Goldsmith and Crawford (2014) tell numerous stories of how data have been used in a "resultoriented" fashion that is synonymous with entrepreneurialism. For them, it is about changing the relationships with governance frameworks from one where unhappy citizens phone and complain about various issues to one in which citizens and local government collaborate to get things fixed. This evolution is in large part driven by needs caused by lower funding available to local government (e.g., austerity) but also by increasing workloads caused by an expanding city and a demographic profile shifting toward more elderly citizens. 
A key call made by Goldsmith and Crawford (2014) is for local government to use data-driven strategies to produce new value from better informed and involved relationships with its citizens:

First, they can empower government employees to use their discretion and common sense, working towards better lives for citizens rather than simply pushing towards increased, narrowly defined activity. Second, these leaders can engage with citizens in the important provision of services, thus thickening the bonds of democracy and the vibrancy of civic life. Third, these digital solutions will enable citizens to work with local government on shared solutions to the grand challenges that confront all Americans.

We see numerous scholars from the discipline of Urban Planning share a "top down" view of a city as the implementation of a master plan (e.g., Anthopoulos \&Vakali, 2012). In a similar administrative view, Bakici et al. (2013) suggest the idea of a smart city rests on three main pillars:

Cities should base their Smart City models on three main pillars-infrastructure, human capital and information-while the Smart City initiative should be a composition of various organisations and departments.

Batty (2017) looks at the idea of a city through the lens of complexity theory and emergent changes from a more complex view of systems (e.g., social, political, economic, etc.). For Batty, the way to understand cities is a bottom-up view of "organic" changes to social structures and social hierarchies and an evolutionary step from what he calls the previous "...architectural determinism and social administration..." approach. As he builds the case for a science-based approach to understanding a city, he sees a city as a network of interrelationships resulting from different types of flow. The idea of a city-science is appealing; if for no other reason it implies that a multifaceted complexity can be managed. However, a problem we see with "bottom up" managerial approaches is they often make assumptions about the strategic context that can lead to ineffectual outcomes.

We can see Schön's (1991) central argument at work in that different individuals schooled in particular professional paradigms make sense of what they see through their "professional lens." The implication of this is that a city can be all of the things the "reliable" scholars utilizing rigorous methods tell us. Therefore, a city as observed is much more complex than any single description can be.

We argue the unit of analysis needs to be more than the empirical city that can be observed; it needs to also allow for the human spirit and collective motivations to play their role in transforming a non-smart city into a smart city. We need to acknowledge the concept of aggregated or collective consciousness (Durkheim, 1984) that opens the way for a city to transform. Key to this is the transactional cost of interacting with others, sharing "know-how" and "information," which helps us begin to glimpse the advantage a city offers over a small rural village. In addition, we need to acknowledge methods, processes, procedures, technology, and people that meld to become the informational infrastructure that enables a widespread rising of social intelligence (Goleman, 2007). We need a more integrated view of a city that evolves into what most would readily agree is a "smart city."

\section{THE EVOLUTIONARY PATH TOIMPROVED CITY-WIDE CONSCIOUSNESS}

Beck and Cowan (1996) talk about different stages of consciousness that are shared in a gestalt relationship between an individual and groups. By and large, these stages bear resemblances to the dominant philosophical paradigms of the past, such as tribes believing in magic and the Renaissance bringing forth a Descartian dualism that leads us to think we are somehow 
disconnected from Nature. Laloux (2014) uses a similar model to talk about the evolution of organizations. Beck, Cowan, and Laloux borrow and adapt from Graves (1970). The point is, we can see a city as an amalgam of many such stages of consciousness functioning simultaneously.

Graves was a psychologist who developed a theory of how individuals experience and cope with the life conditions they face. The different modes of coping oscillate between either a "self-oriented" (i.e., selfish) or "other-oriented" (i.e., selfless) focus. From the individual who feels they are at war with the world to the Machiavellian manipulator, we see numerous examples of coping-styles that are "self-oriented." In contrast we see modes that range from "family," "tribe," army," and "environmentalists" that have a care for others above themselves as individuals (e.g., Mother Theresa in Calcutta). In a city, all examples of coping strategies seem to co-exist in different city-communities, but some dominate others at different points in time.

If we put technology aside for a moment, pause our view of "smart" being some feature of the Internet, we can learn lessons from history. Brook (2013) writes about the evolution of four cities: St. Petersburg, Shanghai, Mumbai, and Dubai. He does so through economic, social, and political perspectives. What we can learn from his work is that cities have evolved around a hierarchy of objectives that sees parallels with a top-down "master plan" approach.

The uppermost objectives are based on creative visions formed around some notion of "progress." From Peter the Great's attempt to recreate a cutting-edge Amsterdam as St. Petersburg to pull a backward Russia into modernization to the British Empire trying to improve the efficiency by which it extracted value from the nations it governed, we see "dominant" core values shape the pursuit of a "futuristic dream," a creative vision.

Alongside "futuristic dreams" of the city is a desire to leverage progress achieved in "the" city to stimulate progress in the wider country, the hinterlands. However, as Brook (2013) shows, this has not always been successful due in large part to the differing levels of consciousness and lack of motivation to pursue the same visions outside the city.

The numerous failed attempts at revolution in Russia prior to 1917 may have started in St. Petersburg, but they could not garner widespread support beyond this large city. It was only when all of Russia was part of World War I, a common threat unifying people and at the same time severe hardship simultaneously experienced by many Russians, that the conditions for the emergence of Bolshevik Communism enabled this particular dominant mind-set to rise and displace established social structures and social hierarchies. The situational context in a city favoring some "bottom-up" ideologies over others, especially when there is a loss of confidence in the existing city's leadership.

Similar historic conflicts between the city and its hinterland can also be seen in Shanghai and Bombay (Brook, 2013). This strengthens our view that cities emerge from a combination of conditions and bottom-up organic growth of social and technical ideas. It also suggests the possibility of a more informed "gestalt" relationship with "top-down" and "bottom-up" initiatives.

We also see the role top-down "dominant power" plays and how it itself adapts or is overthrown. Most cities began with a singular authoritarian leader or leadership layer. From Peter the Great's singular "autocracy" founded on notions of "divine right" to the British Raj's institutionalized "autocracy-as-bureaucracy." We can see a different kind of repeating pattern. As one type of consciousness dominates, others resist. Therefore, conflict is a natural part of the history of cities, but having recognized this pattern we can now transcend it and see new 
possibilities emerge through a more enlightened approach to collaboration among citizens and city hall. That is, conflict need not be so pugilistic and can be fuel for creativity and innovation.

Conflict and frustration flow out of a perceived sense of injustice. History is replete with examples of protest and confrontation between the dominant and dominated. These sources of conflict exist today in many of our modern cities as well as less developed cities. The point is, the convergence between information technology (IT) and communication technology (e.g., wireless) means we need to learn from the past and avoid repeating "dark times" we have seen in transforming cities throughout history. We now have an opportunity to transform our cities more intelligently than ever before.

We have also seen the nature of power shift within cities from colonial (e.g., British Raj in Bombay) to more indigenous class structures (e.g., Westernized upper-middleclass in India) but not necessarily bringing significant change for a city's poorest citizens. History teaches us that dissatisfaction among many city dwellers becomes a feedstock for change in numerous cities. From communist revolutions in Russia and China as well as the Independence of India, we clearly see a common desire for a city that is fair in the way its opportunities and benefits are made available to its citizens.

Brook also shows another tension within the transforming city. The spread of colonialism was driven by a desire for individuals to amass wealth. The role "effort \& reward" played meant some were motivated to make things happen, to take entrepreneurial risks. Where incumbent power systems supported them, this ambition was likely to be successful for the individual but not necessarily good for those exploited. On the other hand, where such a motivation was lacking we see widespread evidence that notions of progress stall. We need a combination of entrepreneurialism and administration as both are necessary in a complex socio-technical city. We see the dilemma a city stands on: on one horn are the incentives given to individuals to drive progress and on the other horn the needs of the many. This is yet another manifestation of Graves's (1970) view of coping systems that reflect the life conditions faced with the reactive inner experiences of people in the various contexts within a complex and dynamic city. We argue technology can be used to enable a more enlightened city, where the experience of being in that city is an important metric.

If our ambition is to build smart cities, places where social intelligence is high, then we can see from history we need at least the four following components:

- A creative vision that is attractive to investors and inhabitants;

- Power expressed through democratic government with open and shared information symmetry among all citizens;

- Incentives for individuals to drive progress with safeguards to prevent exploitation that denies other citizens fair, full, and enjoyable lives in a smart city;

- Technology used to collect data and distribute informationto local government employees and citizens in an "up and down" approach rather than only a "top down" or only a "bottom up" approach.

As top-down approaches and bottom-up approaches make assumptions of each context, what we need is an approach that combines both top and bottom approaches we will call "up and down." 


\section{HOW DO WE BUILD A SMART CITY BIT BY BIT?}

The city comprises groups and individuals with differing levels of consciousness and motivation. We need to adopt the principles of self-organization (Ashby, 1962) and enable citizens to play an active role in building their own smart city so that participative action (Reason \&Bradbury, 2008) reduces change resistance. What is needed are converged IT and wireless solutions linked to the Internet that covers an entire city. Such a provision would be a step closer to ensuring all citizens have a means to enjoy symmetrical information (i.e., no one has a significant information advantage), thus enabling a more meritocratic governance system. In Sheffield, in the north of England, we have seen numerous attempts to get single-focus "point solutions" (Woodhead et al., 2018) to be adopted, but as yet none have become dominant. We see lots of small initiatives trying to grow on their own and in isolation from other initiatives. There is a chicken and egg problem in that a city-wide stream of data is not available for application developers, and trying to justify return on investment on a "single solution" basis is difficult. What is required is a low-cost wireless sensor network that makes data available and allows its infrastructure to be used freely.

A recent large funding success for the University of Sheffield in a project called "Urban Flows" means the infrastructure for a smart city in Sheffield will happen (Urban Flows Observatory, 2018). While this team makes its advances, we decided to proceed without any funding. This meant an "open source" approach and culture was our best option. We started looking for a low-cost network around which we could develop Internet of Things solutions.

Mobile Internet with SIM card technology such as $2 \mathrm{G}, 3 \mathrm{G}, 4 \mathrm{G}$, and $5 \mathrm{G}$ are technologically fantastic for Internet of Things (IoT), but they have a cost that becomes more expensive as a solution scales . We need a way to some low cost "quick wins" that enable start-ups to flourish and kick-start innovative smart city solutions.

Sheffield City Council, the local government in Sheffield, has recently funded a company called Idaq (2018) to roll out free Wi-Fi across Sheffield's city center. This will bring many possibilities to the city center but offers little to the other parts of the city. So we see this as a good first step but would like to see its scope extended across the entire city.

In many cities around the world, an ambition similar to ours has been achieved with a lowpower wide-area network (LPWAN) using low-powered radio technology called LoRaWAN. The open source community has driven a particular version of this technology called "The Things Network" (TTN) (2018). By building a TTN in Sheffield we can make products that also would work in many cities around the world because TTN is already global.

The sensor (e.g., temperature) communicates with a node at the outer edge of a network. This node then communicates to a gateway, a device that interfaces with the Internet. A TTN gateway can handle many thousands of nodes. (We were told 20,000 is possible but have not verified this.)

The problem this technology has is that the TTN gateway can only listen or talk, not both at the same time. So it is ideal for a monitoring system (i.e., one-way data-flow from the sensor through the gateway and Internet to the TTN cloud backend) and if coded to use very small data packet sizes can get close to real time.

Once data gets to the TTN cloud the app developer can get the data to then flow into their application (i.e., an app) through an application program interface (API). If the app needs to push a response back out to the edge it might be better to use mobile phone technology (e.g., $2 \mathrm{G}, 3 \mathrm{G}, 4 \mathrm{G}$, or $5 \mathrm{G}$ ) for that part of the solution. 
A key benefit of TTN is gateways can be shared with anyone, and all packets are encrypted. That is, the first city-wide solution can also be used by other developers, and so we would expect to see waves of innovative capability follow.

There are many online tutorials available, and with cheap electronics a city such asSheffield could get its first city-wide TTN LoRaWAN network and solution with about 1,000 sensor nodes ( $£ 10$ each) and 50 gateways ( $£ 100$ each) for around $£ 15,000$ if volunteers collaborate. In a recent Sheffield University competition called "Urban Flows" a number of contestants built numerous "sensors in a box" (e.g., air quality \& specific gas detection, humidity, temperature, etc.) costing around $£ 150$. With economies of scale a number of contestants thought this cost could be lowered to $£ 50$ per sensorbox. It was also interesting to see a number of contestants were from the hackathons we ran in the Sheffield Hackspace (SHH\&M, 2018). The insight here is, that by making things happen, things happen.

To get started we asked Sheffield Hackspace (SHH\&M, op cit) if they would help. Their response went beyond our expectations. They agreed to host five hackathons where we would help citizens to start building TTN gateways and TTN sensor nodes. We know this will notbe enough in of itself,but it brings understanding into the city, and we hope this becomes part of a mainstream effort.

If we can make a city-wide data layer available, we make app development possible, and it is from that we expect to see lots of new innovations follow. In particular we want to help Sheffield City Council be part of a city-wide transformation that empowers many of its citizens to be more actively engaged in projects to fight "crime, violence, food poverty, fuel poverty, traffic congestion, etc.," as stated in this paper's opening paragraph.

We want to borrow from Goldsmith and Crawford (2014) and use data and information to make the citizens that live in Sheffield (i.e.,Sheffielders) "empowered, engaged and enabled." We want to see everyone's experience of living in Sheffield to be noticeably improved and see our action-science role as getting involved rather than observing from afar. We also hope making Sheffield a smart city will also attract other digital innovators and therebyimprove Sheffield's ability to share knowledge and drive further innovations.

\section{CONCLUSION}

In this paper we explored the idea of what a smart city can be and how we are trying to play our part nudging toward a measurable notion of progress (e.g., developing a foundational LoRaWAN capability). We hope our interpretation of why the world is evolving as it is and how the city is adapting in that macro context to become a true "smart city" opens creative and innovative conversations for action-researchers. Conferences are where new ideas are often aired, and the CSID AUN-SCUD International Conference on Sustainable Infrastructure and Urban Development certainly triggered lots of new ideas and research directions. It is this sharing of ideas that is fundamentally important to invention and later innovation as ideas scale.

The reason the idea of a smart city is necessary is because our cities struggle to cope with the demands placed upon them, and these demands are predicted to grow due to an ever increasing rate of population density with demographic shifts. The need to innovate is upon us, and this requires a move from transactional thinking based around notions of servant leaders and citizens as "customers." It needs everyone in a city, whether a local government employee or resident, to see themselves as "citizens" with a stake in making their city a great place to live, work, and play.

We cited authors that attempt to describe their idea of a city through particular professional perspectives, but there are many more we have not reported on in this paper. The perspectives 
offered by reliable scholarly work provide insights that can help us all; they are valuable. However, we need a way of seeing these different perspectives in a more integrated fashion. We attempt such a synthesis by seeing a city as a place where life-conditions and the citizens' corresponding internal experiences influence decisions that result in what a city becomes. The decisions made by many thousands of citizens is what we want to improve.

We see the idea of a city as a reflection of different types of collective consciousness that are dominant within local government, organizations, and citizens. We believe this "collective consciousness" is a function of the way information is shared as well as its quality. If we can make more pertinent information available to citizens, then we believe their level of awareness, their consciousness, will improve. Furthermore, we argue this will make a city "smarter" than other cities because the quality of decisions made by citizens will be improved.The idea is, as a smart city would have more citizens making better decisions than a non-smart city, it should be noticeably better in regard tonumerous attributes.

Central to this ambition is the need for the following:

- A creative vision that is attractive to investors and inhabitants;

- Power expressed through democratic government with open and shared information symmetry among all citizens;

- Incentives for individuals to drive progress with safeguards to prevent exploitation that denies other citizens from fair, full, and enjoyable lives in a smart city;

- Technology used to collect data and distribute informationto local government employees and citizens in an "up and down" approach rather than only a "top down" or only a "bottom up" approach.

We also discussed our efforts to build a foundational capability in Sheffield around TTN, which was made possible through the support of the Sheffield Hackspace and the open source culture they embody.

We will soon see the arrival of free Wi-Fi in the city center through a project between the local council and a company called Idaq. We will also see a full TTN LoRaWAN coverage across the city through volunteer efforts and the Urban Flows project. What our action research project has done is build foundational capability among about 50 people over five Smart City Hackathons.

Our next action research agenda will be to build specific Internet of Things solutions that again nudge the smart city agenda another couple of steps forward.

\section{REFERENCES}

Anthopoulos, L.G., Vakali, A., 2012. Urban Planning and Smart Cities: Interrelations and Reciprocities. In: The Future Internet. FIA 2012, Álvarez F. et al. (eds.), Lecture Notes in Computer Science, vol. 7281. Springer, Berlin, Heidelberg

Ashby, W.R., 1962. Principles of the Self-organizing System. In: Principles of SelfOrganization: Transactions of the University of Illinois Symposium, Von Foerster, H., Zopf, Jr., G. W., (eds.), Pergamon Press, London, UK, pp. 255-278

Bakici, T., Almirall, E., Wareham, J., 2013. A Smart City Initiative: The Case of Barcelona Journal of the Knowledge Economy, Volume 4(2), pp. 135-148

Batty, A., 2017. The New Science of Cities. MIT Press, Cambridge, MA

Beck, D.E., Cowan, C., 1996. Spiral Dynamics: Mastering Values, Leadership and Change. Blackwell Publishing Ltd. Oxford

Brook, D., 2013. A History of Future Cities. W.W. Norton \& Company, Inc., New York

Durkheim, E., 1984. The Division of Labour in Society (Originally published in 1893). Palgrave Macmillan, Basingstoke 
Goldsmith, S., Crawford, S., 2014. The Responsive City. Jossey-Bass, San Francisco

Goleman, D., 2007. Social Intelligence: The New Science of Human Relationships. Arrow Books, New York

Graves, C.W., 1970. Levels of Existence: An Open System Theory of Values. Journal of Humanistic Psychology, Volume 10(2), pp. 131-155

Idaq, 2018. Idaq Networks to deliver Free Wi-Fi throughout Sheffield City Centre. Available Online at http://www.idaqnetworks.com/news/idaq-networks-to-deliver-free-wi-fithroughout-sheffield-city-centre, Accessed on June 12, 2018

Laloux, F., 2014. Reinventing Organizations: A Guide to Creating Organizations Inspired by the Next Stage in Human Consciousness. Nelson Parker, Brussels

Reason, P., Bradbury, H., (eds.), 2008. The Sage Handbook of Action Research: Participative Inquiry and Practice. London: Sage Publication

Schön, D.A., 1991. The Reflective Practitioner: How Professionals Think in Action. $3^{\text {rd }}$ Edition. London: Arena

SHH+M, 2018. Sheffield Hardware, Hackers \& Makers. Available Online at http://www.sheffieldhardwarehackers.org.uk/wordpress/, Accessed on 6 June 2018

The Things Network (TTN), 2018. The Things Network: Building a Global Internet of Things Network Together. Available Online at https://www.thethingsnetwork.org/, Accessed on 6 June 2018

United Nations (UN), 2014. World's Population Increasingly Urban with more than Half Living in Urban Areas. Available Online at http://www.un.org/en/development/desa/news/population/world-urbanization-prospects2014.html, Accessed on 5 June 2018

United Nations (UN), 2018. 68\% of the World Population Projected to Live in Urban Areas by 2050, Says UN. Available Online at https://www.un.org/development/desa/en/news/population/2018-revision-of-worldurbanization-prospects.html, Accessed on 6 June 2018

Urban Flows Observatory, 2018. Urban Flows Observatory Sheffield. Available Online at http://urbanflows.org.uk/, accessed on 12 June 2018

Woodhead, R.M., Stephenson, P., Morrey, D., 2018. Digital Construction: From Point Solutions to IoT Ecosystem. Automation in Construction, Volume 93, pp. 35-46 